\title{
Lewis Acids Catalyze the Addition of Allylboronates to Aldehydes by Electrophilic Activation of the Dioxaborolane in a Closed Transition Structure
}

\author{
Vivek Rauniyar and Dennis. G. Hall* \\ Department of Chemistry, University of Alberta, Edmonton, AB, T6G 2G2, Canada
}

\section{Supporting Information}

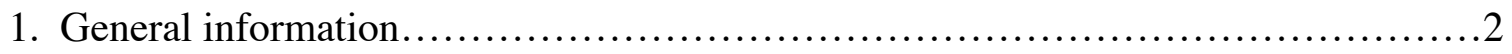

2. Reaction of (Z)-crotyl tri- $n$-butylstannane with hydrocinnamaldehyde.................2

3. Reaction of (E)- crotyl tri- $n$-butylstannane with hydrocinnamaldehyde.............2-3

4. Control experiment with tetra-butyl ammonium triflate ...........................

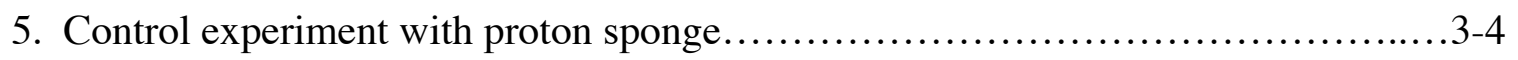

6. Determination of the reaction order for aldehyde and $(E)$-crotyl pinacolboronate....4-5

7. Comparison of the rates of catalyzed vs background reaction.......................5-6

8. Reaction of prenyl-9BBN with benzaldehyde in the absence of $\operatorname{Sc}(\mathrm{OTf})_{3} \ldots \ldots \ldots \ldots \ldots$

9. Reaction of prenyl-9BBN with benzaldehyde in the presence if $\operatorname{Sc}(\mathrm{OTf})_{3} \ldots \ldots \ldots \ldots . .6-7$

10. NMR of kinetic studies with encrypted peak height..............................

11. Graph of kinetic studies............................................... $9-10$

12. Graph of rate comparison.....................................................

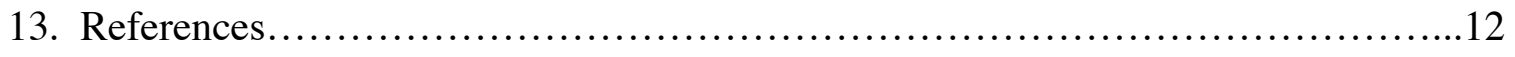




\section{General Information}

Unless otherwise noted, all reactions were performed under argon atmosphere using flame-dried glassware. $\mathrm{CH}_{2} \mathrm{Cl}_{2}$ was distilled over $\mathrm{CaH}_{2}$. THF and $\mathrm{Et}_{2} \mathrm{O}$ were distilled over sodium/benzophenone ketyl. All aldehydes were purified by Kugelrohr distillation prior to use. Thin layer chromatography (TLC) was performed on Merck Silica Gel 60 F254 plates and were visualized with UV light and $5 \%$ phosphomolybdic acid/EtOH (PMA). NMR spectra are recorded on Varian INOVA-300, INOVA 400 or INOVA 500 instruments. Variable temperature spectroscopy at $-80^{\circ} \mathrm{C}$ was recorded on Varian INOVA 400. The residual solvent protons $\left({ }^{1} \mathrm{H}\right)$ or the solvent carbons $\left({ }^{13} \mathrm{C}\right)$ were used as internal standards. Boron NMR spectra are referenced to external $\mathrm{BF}_{3}$. $\mathrm{Et}_{2} \mathrm{O}$. $80 \% E$ crotyl $n$ butyl tin was made by the procedure of Naruta. [1] $100 \% \mathrm{Z}$ crotyl $n$-butyl tin was made by following Schlosser's procedure. [2] Prenyl-9BBN was prepared by hydroboration of 3-methyl-1,2-butadiene. [3] prenyl-pinacolboronate was made by homologation of iodo-methane-pinacolboronate with 2-methyl-1-propenylmagnesium bromide. [4] followed by purification over neutralized silica gel. (E)-crotylpinacolboronate was made by quenching the potassium anion of the corresponding $(E)$ butene with boron tri-isopropoxide, followed by the sequence of acid promoted hydrolysis of the boronate ester and further esterification of the resulting boronic acid with pinacol, and purification over neutralized silica gel. [5] Spectral data of compounds in this study have been previously reported. [1-6]

\section{Reaction of $Z$-crotyl tri- $n$ butyl stannane ( $>99 \%$ cis) with hydrocinnamaldehyde in the presence of $\operatorname{Sc}(\mathrm{OTf})_{3}$.}

To $0.0070 \mathrm{~g}$ of $\mathrm{Sc}(\mathrm{OTf})_{3}$ in a $25 \mathrm{ml} \mathrm{RB}$ flask was added $0.50 \mathrm{ml}$ of freshly distilled DCM and this mixture was cooled to $-78^{\circ} \mathrm{C}$ and maintained for 15 minutes. To above was added $19 \square \mathrm{l}(0.14 \mathrm{mmol}, 1.0$ equiv) of freshly distilled hydrocinnamaldehyde and the solution was allowed to stir for 10 minutes. To above was added $0.050 \mathrm{~g}$ of Z-crotyl tri $n$-butyl stannane (1.0 equiv, $0.14 \mathrm{mmol}$ ) dissolved in $0.5 \mathrm{ml}$ of anhydrous DCM. The reaction mixture was allowed to stir for 19 hours at $-78^{\circ} \mathrm{C}$ after which, $0.29 \mathrm{ml}$ of 1 molar solution of DIBAL-H in toluene was added to quench the aldehyde. The reaction mixture was allowed to stir for 30 minutes at $-78^{\circ} \mathrm{C}$ and then, $3.0 \mathrm{ml}$ of $\mathrm{NaHCO}_{3}$ was added, and the reaction mixture was allowed to warm to RT over one hour. The crude product was extracted with $(10 \mathrm{ml} \times 3)$ of DCM and the combined organic extracts were washed with $10 \mathrm{ml}$ of brine followed by drying over anhydrous $\mathrm{Na}_{2} \mathrm{SO}_{4}$. The crude product was concentrated in vaccuo $\left(16\right.$ torr, $\left.20^{\circ} \mathrm{C}\right)$. Upon ${ }^{1} \mathrm{H}$ NMR analysis of this crude mixture, it was established that there was only one detectable syn product, and \% conversion was established to be only $1.5 \%$. The anti- adduct was not detected even after doing baseline expansions.

\section{Reaction of $E$-crotyl tri- $n$ butyl stannane ( $80 \%$ trans) with hydrocinnamaldehyde in the presence of $\operatorname{Sc}(\mathrm{OTf})_{3}$.}

To $0.0070 \mathrm{~g}$ of $\mathrm{Sc}(\mathrm{OTf})_{3}$ in a $25 \mathrm{ml} \mathrm{RB}$ flask was added $0.50 \mathrm{ml}$ of freshly distilled DCM and this mixture was cooled to $-78^{\circ} \mathrm{C}$ and maintained for 15 minutes. To above was 
added $19 \square 1$ (0.14 mmol, 1.0 equiv) of freshly distilled hydrocinnamaldehyde and the solution was allowed to stir for 10 minutes. To above was added $0.050 \mathrm{~g}$ of $E$-crotyl tri- $n$ butyl Stannane (1.0 equiv, $0.14 \mathrm{mmol}$ ) dissolved in $0.50 \mathrm{ml}$ of anhydrous DCM. The reaction mixture was allowed to stir for 19 hours at $-78^{\circ} \mathrm{C}$ after which, $0.29 \mathrm{ml}$ of $1 \mathrm{M}$ solution of DIBAL-H in toluene was added to quench the aldehyde. The reaction mixture was allowed to stir for 30 minutes at $-78^{\circ} \mathrm{C}$ and then, $3.0 \mathrm{ml}$ of $\mathrm{NaHCO}_{3}$ was added, and the reaction mixture was allowed to warm to RT over one hour. The crude product was extracted with $(10 \mathrm{ml} \times 3)$ of DCM and the combined organic extracts were washed with $10 \mathrm{ml}$ of brine followed by drying over anhydrous $\mathrm{Na}_{2} \mathrm{SO}_{4}$. The crude product was concentrated in vaccuo $\left(16\right.$ torr, $\left.20^{\circ} \mathrm{C}\right)$. Upon ${ }^{1} \mathrm{H}$ NMR analysis of this crude mixture, it was established that there was only one detectable syn product and \% conversion was established to be $33 \%$. The anti- adduct was not detected even after doing baseline expansions.

\section{Control experiment with $\mathrm{Bu}_{4}$ NOTf:}

$0.0070 \mathrm{~g}$ of $\mathrm{Bu}_{4} \mathrm{NOTf}(0.10 \mathrm{eq}, 0.020 \mathrm{mmol})$ was dissolved in $0.50 \mathrm{ml}$ of freshly distilled $\mathrm{DCM}$ and cooled to $-78^{\circ} \mathrm{C}$. To the solution was added $25 \square 1$ (1.0 equiv, $\left.0.20 \mathrm{mmol}\right)$ of hydrocinnamaldehyde and the mixture was maintained at $-78^{\circ} \mathrm{C}$ for 15 minutes. To above slowly added $42 \mathrm{mg}(0.23 \mathrm{mmol})$ of $E$-crotyl pinacolboronate dissolved in $0.50 \mathrm{ml}$ of freshly distilled DCM and the reaction mixture was stirred for 18 hours at $-78^{\circ} \mathrm{C}$, after which the aldehyde was quenched with $0.38 \mathrm{ml}$ of DIBAL-H (2.0 equiv) and allowed to stir for 30 minutes. To above was added $0.76 \mathrm{ml}$ of $\mathrm{I} \mathrm{N} \mathrm{HCl}$ at $-78^{0} \mathrm{C}$ and the reaction mixture was brought to room temperature over a period of 1 hour. The crude product was extracted with ether $(10 \mathrm{ml} \mathrm{x} 3)$ and the combined ethereal extracts were washed with brine $(10 \mathrm{ml})$ and dried over anhydrous $\mathrm{Na}_{2} \mathrm{SO}_{4}$. The mixture was concentrated in vaccuo $\left(16\right.$ torr, $\left.20^{\circ} \mathrm{C}\right)$ to give the crude product which was analyzed for $\%$ conversion. Upon ${ }^{1} \mathrm{H}$ NMR analysis of the ratio of carbinol protons of the homoallylic alcohol to that of the reduced aldehyde; olefinic protons vs triplet at $3.65 \mathrm{ppm}, \%$ conversion was established to be $2.9 \%$.

\section{Control Experiment with Proton Sponge:}

$0.012 \mathrm{~g}$ of $\mathrm{Sc}(\mathrm{OTf})_{3}(0.1$ equiv, $0.025 \mathrm{mmol})$ was added $0.75 \mathrm{ml}$ of freshly distilled DCM and the suspension was cooled to $-78^{\circ} \mathrm{C}$. To above solution under positive pressure of argon was added $0.0054 \mathrm{~g}$ ( 0.1 equiv, $0.025 \mathrm{mmol}$ ) of proton-sponge [1,8bis-(dimethyl amino)-naphthalene]. This was followed by addition of $29 \square$ of $p$ tolualdehyde ( 1.0 equiv, $0.25 \mathrm{mmol}$ ). This mixture was maintained at $-78^{0} \mathrm{C}$ for 15 minutes. This was followed by slow addition of $0.075 \mathrm{~g}$ of $E$-crotyl pinacolboronate dissolved in $1.0 \mathrm{ml}$ of DCM. The reaction mixture was allowed to stir for 19 hours after which the aldehyde was quenched with $0.75 \mathrm{ml}$ of DIBAL-H (2.0 equiv), and allowed to stir for 30 minutes. To above was added $1.5 \mathrm{ml}$ of $\mathrm{IN} \mathrm{HCl}$ at $-78^{\circ} \mathrm{C}$ and the reaction mixture was brought to room temperature over a period of 1 hour. The crude product was extracted with Ether $(20 \mathrm{ml} \times 3)$ and the combined ethereal extracts were washed with brine $(10 \mathrm{ml})$ and dried over anhydrous $\mathrm{Na}_{2} \mathrm{SO}_{4}$. The mixture was concentrated in vaccuo $\left(16\right.$ torr, $\left.20^{\circ} \mathrm{C}\right)$ to give the crude product which was analyzed for \%. Analysis of the ratio of carbinol hydrogen of product; doublet at $4.4 \mathrm{ppm}$ with that of the benzylic hydrogen's of the reduced aldehyde; singlet at $4.7 \mathrm{ppm}$ gave $\%$ conversion of $>99 \%$. We 
also ran the same reaction with 2,6,-di-tert butyl-methyl pyridine as a proton abstractor, and obtained a percent conversion of $39 \%$. This low conversion may in fact be due to partial inhibition of the catalyst by the additive.

\section{Determination of the rate orders of aldehyde and $(E)$-crotyl-pinacolboronate}

\section{A. Aldehyde $=1$ equiv. $(E)$-crotyl-pinacolboronate $=1$ equiv. $\operatorname{Sc}(O T f)_{3}=0.1$ equiv}

Freshly prepared $(E)$-crotyl-pinacolboronate $(0.18 \mathrm{~g}, 1.0 \mathrm{mmol})$ was dissolved in $\mathrm{d}_{2}$-DCM to make a $1 \mathrm{M}$ solution. Freshly distilled $p$-tolualdehyde $(0.12 \mathrm{ml}, 1.0 \mathrm{mmol})$ was dissolved in $\mathrm{d}_{2}$-DCM to make a $1 \mathrm{M}$ solution. Scandium triflate $(0.017 \mathrm{~g}, 0.035 \mathrm{mmol})$ was added to a dry NMR tube, and was flushed with argon. To the catalyst in the NMR tube at $-78^{0} \mathrm{C}$ was added $0.35 \mathrm{ml}(0.35 \mathrm{mmol})$ of $1 \mathrm{M}$ solution of $p$-tolualdehyde and this mixture was maintained at $-78^{\circ} \mathrm{C}$ for 10 minutes. To above was added $0.35 \mathrm{ml}(0.35$ mmol) of $1 \mathrm{M}$ solution of $(E)$-crotyl-pinacolboronate and this reaction mixture was analyzed for product formation by variable temperature NMR spectroscopy. The experiment was run in a pre-acquisition delay mode (PAP) at $-80^{\circ} \mathrm{C}$. The change in the product composition over time, in the reaction mixture, was analyzed for by measuring the relative peak heights of the carbinol proton of the borate product; doublet at 4.72 $4.742 \mathrm{ppm}$.

A graph of the change in peak height over time provided the slope (rate of the reaction) of this reaction. The equation of the line generated is $y=0.0011 x+0.5528$ with (the $R^{2}$ value of 0.992). This slope was the reference for determination of rate orders of $p$ tolualdehyde and $(E)$-crotyl-pinacolboronate.

\section{B. Aldehyde $=2$ equiv. $(E)$-crotyl-pinacolboronate $=1$ equiv. $\operatorname{Sc}(O T f)_{3}=0.1$ equiv.}

Freshly prepared $(E)$-crotyl-pinacolboronate $(0.18 \mathrm{~g}, 1 \mathrm{mmol})$ was dissolved in $\mathrm{d}_{2}$-DCM to make a $1 \mathrm{M}$ solution. Freshly distilled $p$-toluelaldehyde $(0.24 \mathrm{ml}, 2.0 \mathrm{mmol})$ was dissolved in $\mathrm{d}_{2}$-DCM to make a $2 \mathrm{M}$ solution. Scandium triflate $(0.017 \mathrm{~g}, 0.035 \mathrm{mmol})$ was added to a dry NMR tube, and was flushed with argon. To the catalyst in the NMR tube at $-78^{0} \mathrm{C}$ was added $0.35 \mathrm{ml}(0.35 \mathrm{mmol})$ of $1 \mathrm{M}$ solution of $p$-toluelaldehyde, and this mixture was maintained at $-78^{0} \mathrm{C}$ for 10 minutes. To above was added $0.35 \mathrm{ml}(0.35$ $\mathrm{mmol})$ of $1 \mathrm{M}$ solution of $(E)$-crotyl-pinacolboronate and this reaction mixture was analyzed for product formation by variable temperature NMR spectroscopy. The experiment was run in a pre-acquisition delay mode (PAP) at $-80^{\circ} \mathrm{C}$. The change in the product composition over time, in the reaction mixture, was analyzed for by measuring the relative peak heights of the carbinol proton of the borate product; doublet at 4.72-4.74 ppm.

A graph of the change in peak height over time gave the slope (rate of the reaction) of this reaction. The equation of the line generated is $y=0.0025 x-0.7393$ with (the $R^{2}$ value of 0.9529$)$. The ratio of the slope obtained (0.0025) to that of reference $(\mathbf{6 A}$ 0.0011 ) is 2.1818 , and the ratio of $\log 2.1818 / \log 2$ (which comes from doubling the concentration of the aldehyde w.r.t reference reaction) implies a rate order of 1.13 for $p$ tolualdehyde in the rate equation. 
6C. Aldehyde $=1$ equiv. $(E)$-crotyl-pinacolboronate $=1$ equiv. $\operatorname{Sc}(O T f)_{3}=0.1$ equiv.

Freshly prepared $(E)$-crotyl-pinacolboronate $(0.36 \mathrm{~g}, 2.0 \mathrm{mmol})$ was dissolved in $\mathrm{d}_{2}$-DCM to make a $2 \mathrm{M}$ solution. Freshly distilled $p$-tolualdehyde $(0.24 \mathrm{ml}, 2.0 \mathrm{mmol})$ was dissolved in $\mathrm{d}_{2}$-DCM to make a $2 \mathrm{M}$ solution. Scandium triflate $(0.017 \mathrm{~g}, 0.035 \mathrm{mmol})$ was added to a dry NMR tube, and was flushed with argon. To the catalyst in the NMR tube at $-78^{0} \mathrm{C}$ was added $0.35 \mathrm{ml}(0.35 \mathrm{mmol})$ of $1 \mathrm{M}$ solution of $p$-tolualdehyde, and this mixture was maintained at $-78^{\circ} \mathrm{C}$ for 10 minutes. To above was added $0.35 \mathrm{ml}(0$. $35 \mathrm{mmol}$ ) of $1 \mathrm{M}$ solution of $(E)$-crotyl-pinacolboronate and this reaction mixture was analyzed for product formation by variable temperature NMR spectroscopy. The experiment was run in a pre-acquisition delay mode (PAP) at $-80^{\circ} \mathrm{C}$ The change in the product composition over time, in the reaction mixture was analyzed for by measuring the relative peak heights of the carbinol proton of the borate product; doublet at 4.72-4.74 ppm.

A graph of the change in peak height over time gave the slope (rate of the reaction) of this reaction. The equation of the line generated is $y=0.0024 x-0.0469$ with the $R^{2}$ value of 0.9812 . The ratio of the slope obtained $(0.0025)$ to that of reference $(\mathbf{6 A} 0.0011)$ is 2.2727, and the ratio of $\log 2.2727 / \log 2$ (which comes from doubling the concentration of the reagent compared to reference reaction) implies a rate order of 1.18 for the $(E)$-crotyl-pinacolboronate in the rate equation.

For all of the above runs, the data was collected until the $\%$ conversion of the aldehyde was approximately $0-15 \%$. It was assumed that this portion of the data would provide a representative tangent to the initial rate, thereby giving a reliable reaction order. The experimental results were satisfactorily reproduced for each run.

\section{Comparisons of the rates of reaction between $\operatorname{Sc}(\mathrm{OTf})_{3}$ catalysed allylboration and the background reaction:}

Preparation of Standard Solutions:

$0.20 \mathrm{~g}(1.0 \mathrm{mmol})$ of prenyl-pinacolboronate was dissolved in $\mathrm{d}_{2}$-DCM to make a $1 \mathrm{M}$ solution. $0.14 \mathrm{ml}(1.0 \mathrm{mmol})$ of freshly distilled hydrocinnamaldehyde was dissolved in $\mathrm{d}_{2}$-DCM to make a $1 \mathrm{M}$ solution.

$\mathrm{Sc}(\mathrm{OTf})_{3}$ catalyzed reaction: To a clean and dry NMR tube was added $0.012 \mathrm{~g}$ of $\mathrm{Sc}(\mathrm{OTf})_{3}$ and the tube was flushed with argon and cooled to $-78^{\circ} \mathrm{C}$. To above was added $0.25 \mathrm{ml}$ of $1 \mathrm{M}$ solution of hydrocinnamaldehyde and the mixture was maintained at $-78^{\circ} \mathrm{C}$ for 10 minutes, after which was added $0.25 \mathrm{ml}$ of $1 \mathrm{M}$ solution of prenyl-pinacol boronate. The reaction mixture was analyzed for product formation by variable temperature NMR spectroscopy. A graph of extrapolated \% conversion with time gave the equation of $\mathrm{y}=0.0866 \mathrm{x}+1.4133$ with $\mathrm{R}^{2}=0.9518$.

Background reaction: To a clean dry NMR tube was added $0.25 \mathrm{ml}$ of $1 \mathrm{M}$ solution of hydrocinnamaldehyde and the mixture was maintained at $-78^{\circ} \mathrm{C}$ for 10 minutes, after 
which $0.25 \mathrm{ml}$ of $1 \mathrm{M}$ solution of dimethyl allylboronate was added. The reaction mixture was analyzed for product formation by variable temperature NMR spectroscopy. A graph of extrapolated \% conversion with time gave the equation of $y=0.0006 x+2.2868$ with $\mathrm{R}^{2}=0.9509$. The ratio of the slopes of catalysed and background reaction is 144 , which implies that the speed of catalyzed reaction is approximately 2 orders of magnitude faster than the uncatalysed reaction

\section{Experimental of the reaction of benzaldehyde with prenyl-9BBN in the absence of $\operatorname{Se}(\mathrm{OTf})_{3}$}

Preparation of prenyl-9BBN: $0.040 \mathrm{~g}(0.17 \mathrm{mmol})$ of 9BBN-dimer was weighed into a flask under argon atmosphere and dissolved in $1.0 \mathrm{ml}$ of freshly distilled THF and to above at room temperature was added $0.036 \mathrm{ml}(1.1$ equiv, $0.36 \mathrm{mmol})$ of 3-methyl-1,2butadiene. The reaction mixture was allowed to stir for 2 hours after which the solvent (THF) and unreacted allene were distilled under high vacuum. This was followed by addition of $2 \mathrm{ml}$ of freshly distilled DCM and the solution was stirred for 15 minutes, after which the solvent was removed under high vacuum, and the process was repeated again. The yield for this reaction was assumed to be $50 \%$ so that there is ample reagent for the upcoming step; which amounts to $0.23 \mathrm{mmol}$ of prenyl-9BBN obtained.

This reagent was then dissolved in $1.0 \mathrm{ml}$ of freshly distilled DCM and cooled to $-78^{\circ} \mathrm{C}$. To above was added $0.019 \mathrm{ml}(1.0$ equiv, $0.19 \mathrm{mmol})$ of freshly distilled benzaldehyde and the solution was maintained at $-78^{\circ} \mathrm{C}$ for 15 minutes and the reaction mixture was stirred for 20 minutes at $-78^{\circ} \mathrm{C}$ after which the aldehyde was quenched with $0.38 \mathrm{ml}$ of DIBAL-H and stirred for 30 minutes. This was followed by addition of $0.13 \mathrm{ml}$ of $3 \mathrm{M}$ $\mathrm{NaOH}$ (1.2 equiv with respect to the moles of prenyl-9BBN, that was produced initially in the preparation of the reagent) and $0.13 \mathrm{ml}$ of $30 \% \mathrm{H}_{2} \mathrm{O}_{2}$ at $-78^{\circ} \mathrm{C}$. The reaction mixture was gradually warmed to room temperature and allowed to stir overnight under argon atmosphere. The crude product was extracted with ether $(10 \mathrm{ml} \times 3)$ and the combined ethereal extracts were washed with brine $(10 \mathrm{ml})$ and dried over anhydrous $\mathrm{Na}_{2} \mathrm{SO}_{4}$. The mixture was concentrated in vaccuo $\left(16\right.$ torr, $\left.20^{\circ} \mathrm{C}\right)$ to give the crude product which was analyzed for $\%$ conversion.

Upon ${ }^{1} \mathrm{H}$ NMR analysis of the Benzylic alcohol protons of the reduced aldehyde to the olefinic protons of the homoallylic alcohol, \% conversion was established to be $74 \%$.

\section{Experiment of the reaction of benzaldehyde with prenyl-9BBN in the presence of $\operatorname{Sc}(\text { OTf })_{3}$}

Preparation of Dimethyl allylboronate: $0.048 \mathrm{~g}(0.20 \mathrm{mmol})$ of 9BBN-dimer was weighed into a flask under argon atmosphere and dissolved in $1.0 \mathrm{ml}$ of freshly distilled THF and to above at room temperature was added $0.043 \mathrm{ml}$ (1.1 equiv, $0.44 \mathrm{mmol}$ ) of 1,1 dimethyl allene. The reaction mixture was allowed to stir for 2 hours after which the solvent (THF) and unreacted allene were distilled under high vacuum. This was followed by addition of $2 \mathrm{ml}$ of freshly distilled DCM and the solution was stirred for 15 minutes, after which the solvent was removed under high vacuum, and the process was repeated again. The yield for this reaction was assumed to be $50 \%$ so that there is ample reagent for the upcoming step; which amounts to $0.28 \mathrm{mmol}$ of prenyl-9BBN.

This reagent was then dissolved in $1.0 \mathrm{ml}$ of freshly distilled DCM and cooled to $-78^{\circ} \mathrm{C}$, To above under positive pressure of argon was added $0.010 \mathrm{~g}(0.023 \mathrm{mmol}, 0.10$ equiv 
with respect to the aldehyde) of $\mathrm{Sc}(\mathrm{OTf})_{3}$ The resulting mixture was then maintained at $-78^{\circ} \mathrm{C}$ for 10 minutes. To above was added $0.024 \mathrm{ml}(1.0$ equiv, $0.23 \mathrm{mmol})$ of freshly distilled benzaldehyde and the solution was maintained at $-78^{\circ} \mathrm{C}$ for 15 minutes and the reaction mixture was stirred for 20 minutes at $-78^{\circ} \mathrm{C}$ after which the aldehyde was quenched with $0.46 \mathrm{ml}$ (2.0 equiv) of DIBAL-H and stirred for 30 minutes. This was followed by addition of $0.16 \mathrm{ml}$ of $3 \mathrm{M} \mathrm{NaOH}$ (1.2 equiv with respect to the moles of prenyl-9BBN produced initially in the preparation of the reagent) and $0.16 \mathrm{ml}$ of $30 \%$ $\mathrm{H}_{2} \mathrm{O}_{2}$ at $-78^{0} \mathrm{C}$. The reaction mixture was gradually warmed to room temperature and allowed to stir overnight under argon atmosphere. The crude product was extracted with ether $(10 \mathrm{ml} \mathrm{x} 3)$ and the combined ethereal extracts were washed with brine $(10 \mathrm{ml})$ and dried over anhydrous $\mathrm{Na}_{2} \mathrm{SO}_{4}$. The mixture was concentrated in vaccuo $\left(16\right.$ torr, $\left.20^{\circ} \mathrm{C}\right)$ to give the crude product which was analyzed for \% conversion.

Upon ${ }^{1} \mathrm{H}$ NMR analysis of the benzylic alcohol protons of the reduced aldehyde to the olefinic protons of the homoallylic alcohol, \% conversion was established as $68 \%$.

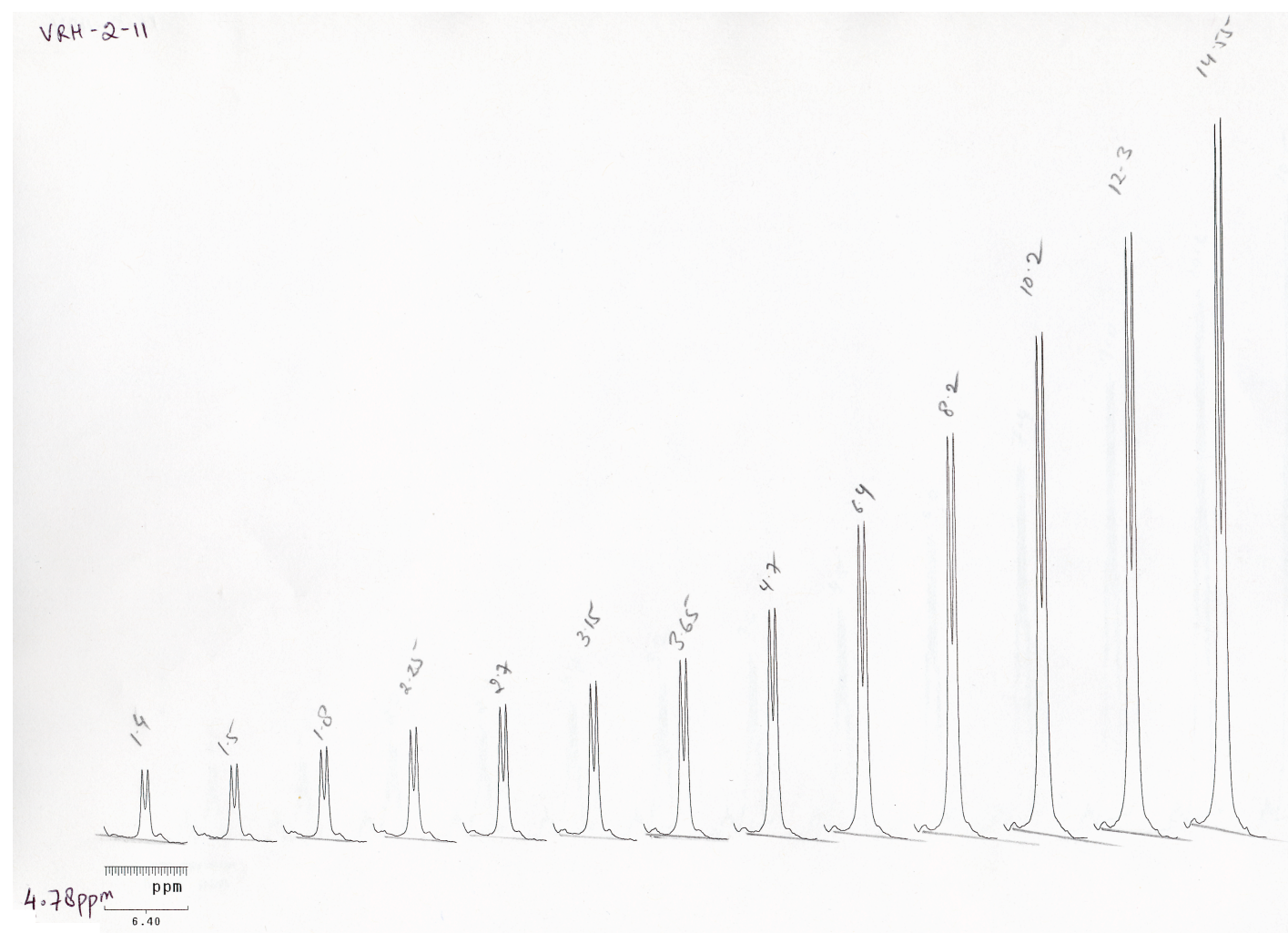

6A. Aldehyde $=1$ equiv. $(E)$-crotyl-pinacolboronate $=1$ equiv. $\operatorname{Sc}(\text { OTf })_{3}=0.1$ equiv

Pad (sequential delay between each spectra) $=0,60,300,300,300,300,300,900,900$, 900, 900, 900.

Actual time for spectra at delay of $0=10$ minutes from starting point of reaction. 


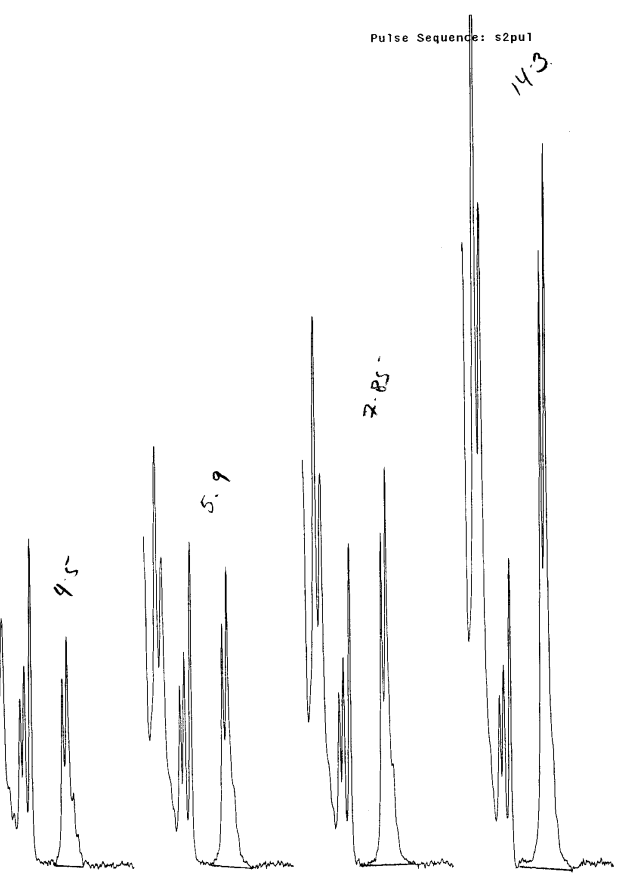

6B. Aldehyde $=2$ equiv, $(E)$-crotyl-pinacolboronate $=1$ equiv, $\operatorname{Sc}(\mathrm{OTf})_{3}=0.1$ equiv .

Pad (sequential delay between each spectra) $=0,300,300,300,300,300,300,900$. Actual time for spectra at delay of $0=10$ minutes from starting point of reaction. 


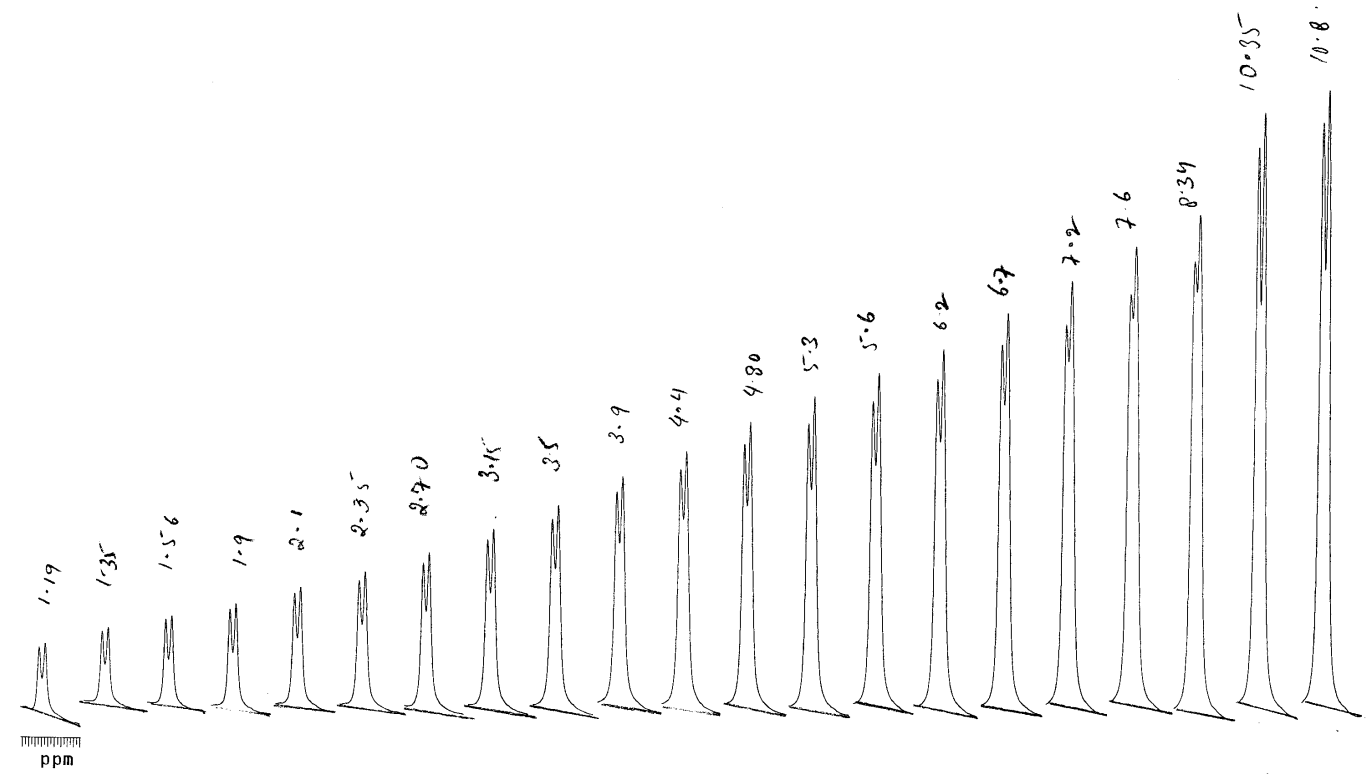

6C. Aldehyde $=1$ equiv. $(E)$-crotyl-pinacolboronate $=2$ equiv. $\operatorname{Sc}(O T f)_{3}=0.1$ equiv.

Pad (sequential delay between each spectra) $=0,120,120,120,120,120,120,120,120$, 120, 120, 120, 120, 120, 120, 300, 300, 300, 300, 300, 300, 300, 300.

Actual time for spectra at delay of $0=3$ minutes from starting point of reaction.

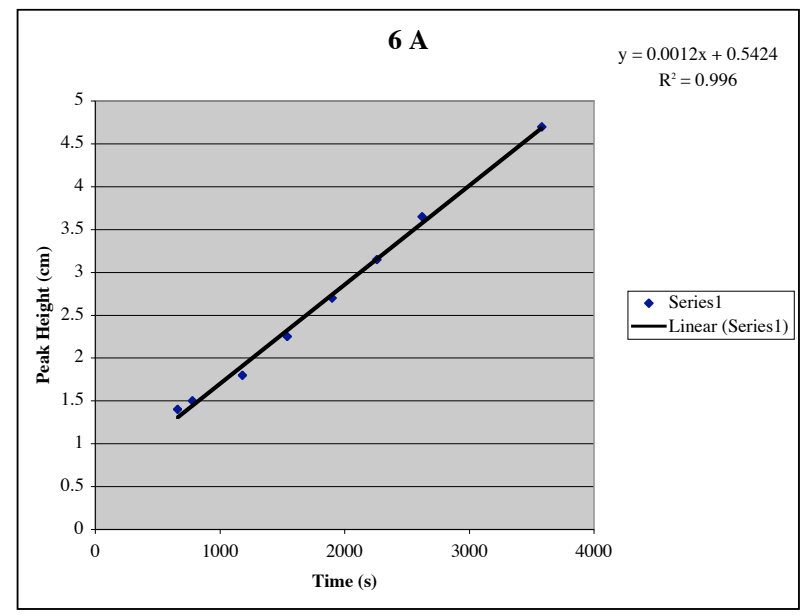

6A. Aldehyde $=1$ equiv. $(E)$-crotyl-pinacolboronate $=1$ equiv. $\operatorname{Sc}(O T f)_{3}=0.1$ equiv. 


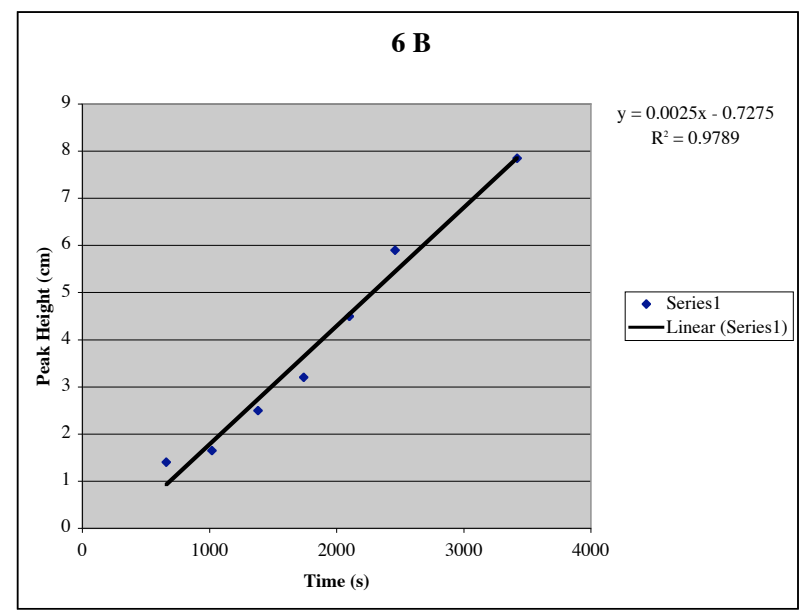

6B. Aldehyde $=2$ equiv. $(E)$-crotyl-pinacolboronate $=1$ equiv. $\operatorname{Sc}(O T f)_{3}=0.1$ equiv.

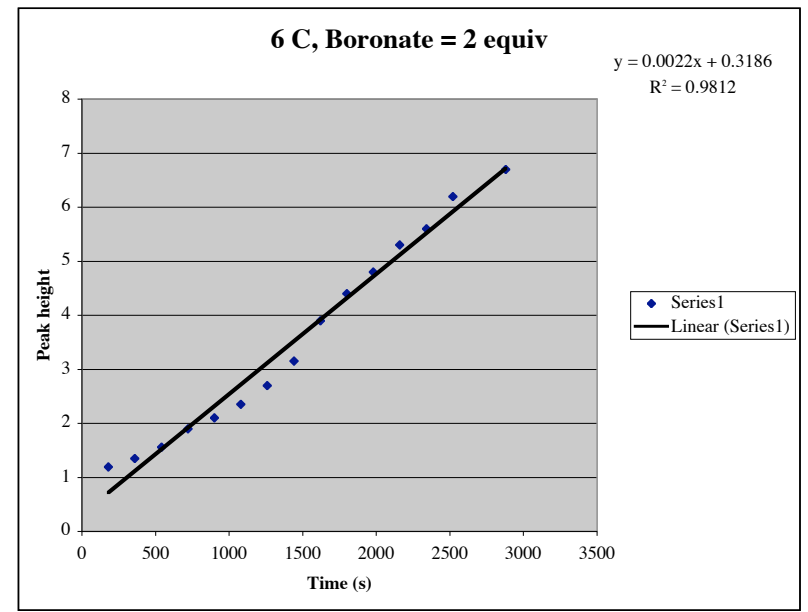

6C. Aldehyde $=1$ equiv. $(E)$-crotyl-pinacolboronate $=2$ equiv. $\operatorname{Sc}(O T f)_{3}=0.1$ equiv. 

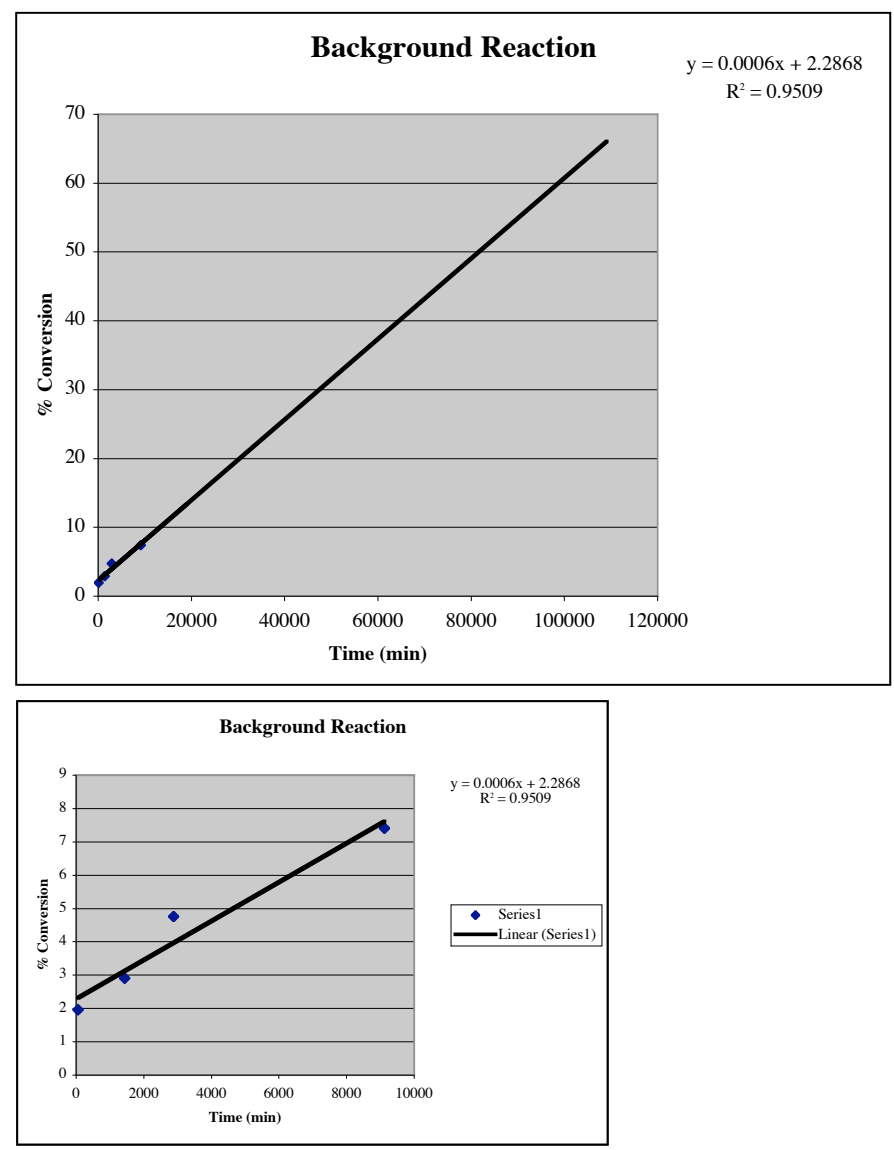

Uncatalysed background reaction between prenyl-pinacolboronate and hydrocinnamaldehyde

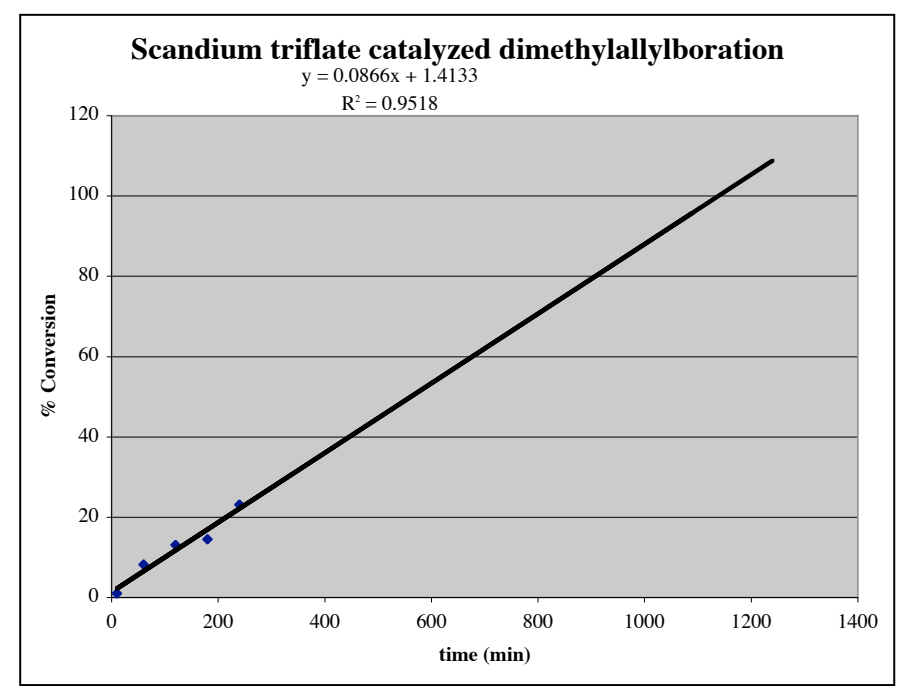

Graph of scandium triflate catalyzed reaction between prenyl-pinacolboronate and hydrocinnamaldehyde 


\section{References:}

[1] Naruta. G.; Maruyama, K. Chemistry Letters. 1979, 881.

[2] Schlosser, Manfred.; Desponds, Olivier. J. Organometallic Chemistry. 1991, 409, 93-101.

[3] Soulie. J.; Cadiot. P. Tetrahedron lett. 125, No. 12, 1215-1218.

[4] Hoffmann, W. Reinhard.; Schlapbach, Achim. Tetrahedron. 1992, 48, No 11. pp 1959-1968.

[5] Lachance, Hugo.; Gravel, Michel.; Lu. Xiasong. Hall, Dennis. G; J. Am. Chem. Soc. 2003, 125, 10160-10161 and Roush, William. R.; Ando, K.; Powers, Daniel. B.; Palkowitz, Alan. D.; Halterman, Ronald. L. J. Am. Chem. Soc. 1990, 112, 6339-6348.

[6] Kobayashi, Shu.; Nishio, Koichi. J. Org. Chem. 1994, 59. 6620-6628 